\title{
Color Coded Cards for Student Behavior Management in Higher Education Environments
}

\author{
Wadee Alhalabi ${ }^{1,2}$,and Mobeen Alhalabi ${ }^{1}$ \\ ${ }^{1}$ Department of Computer Science, Faculty of Computing and Information Technology, King Abdul Aziz University, Jeddah, Saudi \\ Arabia, ${ }^{2}$ Department of Computer Science, College of Engineering, Effat University, Jeddah, \\ Saudi Arabia
}

\begin{abstract}
The Color Coded Cards system as a possibly effective class management tool is the focus of this research. The Color Coded Cards system involves each student being given a card with a specific color based on his or her behavior. The main objective of the research is to find out whether this system effectively improves students' behavior, thus leading to better class management. The research was conducted with 350 students as subjects, and the data were gathered by means of a questionnaire administered over a period of three years. A qualitative method was applied to analyze the results and draw precise conclusions. The results were interesting and promising.
\end{abstract}

Keywords: reward system, class management, color coded cards

\section{Introduction}

Students' academic engagement and pro-social behavior can be improved with efficient classroom management. The process we are proposing here is focused on creating and maintaining appropriate student behavior within classroom settings. Efficiently implemented classroom management strategies can work wonders across diverse subject streams and different grade levels. Within a tiered model where adequate support is provided by the school or college administrators, classroom management programs can be very effective.

However, while there is a professional responsibility to efficiently manage the classroom, there is no science that will automatically confer skills in this particular area. It is obvious that good classroom management is a special skill of teachers that takes time to acquire and master. Clearly, good teaching requires a number of skills in managing a myriad of duties and situations within the classroom.

Surveys of the graduates of most of the educational institutions in the area where this study was conducted have shown that a major concern is the inability of new tutors to efficiently manage the classroom. This problem exists in many academic institutions. Entry-level tutors have great difficulty in effectively managing the 
students in the classroom (Emmer, E. T. \& Sabornie, E. J, 2015). While we cannot derive a generic conclusion about this situation, as one solution cannot fit all of its variations, here is an essential list of things that might be of help under most circumstances. Classroom management skills must be developed by tutors as a crucial part of an efficient system of teaching and practice. These skills are acquired over time through rigorous practice, feedback, and the complete willingness of the tutor to learn and grow in the domain of teaching. Some of the basic factors that must be considered by any tutor who desires to be better in handling different situations are common sense, presence of mind, and a sense of fairness combined with courage, consistency, skills, and expertise in the subject matter of the course. Overall, a tutor must be able to see all the students from their perspective. This efficient monitoring and supervision helps with efficient classroom management.

\section{Literature Review}

School class management is very important for keeping discipline in the classroom and on the overall campus. When class management is done properly, students get more attention from their teachers and they pay more attention to their studies and the curriculum. In order to achieve an excellent educational environment on the school campus, all the teachers, educators, lab instructors, and other administrative officers must take class management as a challenge, and go through different processes to apply better class management methods (Starr, 2010). The aim of all behavior management techniques is to enable students to take ownership of their behavior in a manner respectful of the rights of others (Emerson, 1995). One approach to achieve this result is through positive behavioral support, an approach developed as an alternative to manage students with disabilities who engaged in self-endangering and aggressive behavior. "Positive behavioral support is a general term that refers to the application of positive behavioral interventions and systems to achieve socially important behavior change.” (Sugai et al., 2000, p. 133). Positive behavioral support integrates behavioral sciences, social values and systems perspectives.

One method of providing positive behavioral support is the color coded cards system, which is the topic of this paper. In the following section, two different types of class management tools are presented. Though there are some differences in names, number of colors, and ways of expression, there are similarities in their processes.

\section{Behavior Management Pocket Chart}

Powerful pocket chart systems can help students take responsibility for their own behavior and traits. When they are unable to score high in this system it badly affects their self-esteem. Similarly, when they are unable to acquire the best colors provided by the system their image declines among their classmates. The best color is green, which means they are fine in behavior as per the assessment of the tutor. Yellow represents a warning. Simple color-coding practices aid the students to see, at a glance, each other's status. They strive to work towards earning better colors. The whole idea is communicated to the parents, too. Progress cards point out to the parents the children's behavior in the academic institution.

Some important aspects of efficiently managing a classroom are (a) framing the rules chart; (b) making the points clearly understood by each student; (c) explaining why the rules are necessary and what happens if there are no rules at all in the classroom; (d) listening to the students' comments and opinions in order to know more about their thought processes, and to point them in the right direction; and (e) letting the students start every day with a green card, to begin the day as though they are doing fine. During the day, the students that are not following one of the rules are asked to remove the green and to bring the yellow card to the front of their pockets. This has an impact on the students, forcing them to pay attention to their own behavior in the classroom. Continuously failing to follow the rules means the student will be given an orange card, which 
indicates that there are consequences that will be faced due to the wrong behavior. Finally, when the orange is removed and the red card is shown, the student has had a series of wrong actions; this means that there will be some strict reprimands and serious consequences such as asking the student to go and meet the headmaster, principal, or other appropriate member of the management. At the end of each week, the records are sent to parents so they can see the behavior of their children. The parents must sign these records and send them back to the school management. This shows they know what has happened in the school, and they can take action and motivate their children towards improvement (Jenna, 2016).

There is a possibility of engaging parents and guardians in the students' education and behavior management (Zhang et al., 2015). This could be achieved by exposing the class management system through social media. It would be a great idea to incorporate the color coded card system with social media, so the family are fully aware of the students' achievements and behavior. The teacher's intention is to use information and communication technology (ICT) in this way to motivate the students (Boe, Gulbrandsen, \& Sorebo, 2015). The study reported in Boe et al. (2015) gives a clear indication that if we incorporate ICT in future work, this would have greater impact on student motivation. Buckley studied knowledge sharing through a community of practice (CoP). Most of the participants in that study supported and accepted the CoP elements or features (Buckley, 2012). Such a study encourages us as researchers in the same area to facilitate this technique. However, we did not include the technique in our paper, but we are considering it in future work.

\section{Color Coded Card System}

A well-defined color coded card system must break down the school hours into sections, two or three per day. Based on these sections, the students are rewarded with the rank they have earned during the course of the day. The ultimate goal is to address the behavior of the students, so half-day positions in terms of colors gained will show at a glance the grade of the student to the others. As time passes and the students become accustomed to the concepts and the best approaches to stay within the top ranks, then the understanding of how to behave in the classroom environment is deeper. It shows that they are well trained to adapt to the situational needs of the classroom and to follow the rules and regulations. The students are delighted to earn colors, and this positive enforcement of behavior is very effective in the institutional environment. In addition, it shows clearly to the parents the behavior of the students at the end of each school day.

In our paper, the results of using four color codes are discussed: white and green for rewards, yellow and red for penalties. Students having an outstanding performance in the class are rewarded with white cards, while green is given for actions relevant to helping the authorities. Similar studied was perfrmed using three colors in elementary school (Glenda,, 2004). Ultimately, this paper demonstrates that the positive behavior of the students can be reinforced by the implementation of a color-coded card system, or a ticket system or any other system set up in the classroom. In addition, by applying this system from early ages, specific learning patterns are understood and the correct behavior becomes second nature. This system underlines the need for rules and emphasizes that following rules (not just in school but also in social situations) is a positive aspect of behavior that ensures that the individual follows the general rules defined by society. This is what motivates the students to be more responsible individuals, thus leading to a better future for humankind as a whole. The role of the teacher and the academic curriculum has a big influence in redefining tomorrow for all of humankind. Understanding that responsibility when framing the rules in the chart, and making it simple enough to be understood by the student in the classroom are important aspects of teaching that must not be neglected. 


\section{Negative Impact of Behavioral Assessment Systems}

It can be useful to assess the results of this system in the classroom. A series of specific actions common to the shame-based systems are taken into consideration. In some cases, instead of producing the desired effects, the results were not productive. For example, consider the situation where the card earned is yellow instead of green. The general consensus is that the student will try to earn a better card soon. For this, he or she must behave according to the rules set for all students in that specific environment. When they misbehave, seeing their name on the board with the corresponding grade should be a clear-cut reminder of their poor behavior choice.

When a student misbehaves and is listed, he or she is isolated and gains a different identity, being recognized in the student's community in a different way (Shindler, 2009). On some level, this facilitates them to meet some basic needs. Students that have received such notices again and again receive attention. First time offenders may only get confused about the state of their actions and position in the group. However, repeated listing on the chart attracts recognition. The power to bring their name to the board as often as possible is assumed to be a power to gain attention. Changing cards does not require a big effort and it is often done any time they need to gain favors from parents or the person in change. Being recognized feels good for some kids. Psychologically, the unconscious mind does not make the distinction if the attention is good or bad, but loves to be recognized. Simply put, most forms of attention lead to good feelings, as compared to lack of attention. Tolerating a temporary sense of embarrassment in public is not a big deal for these students who get used to it. Shame based behavioral assessment can be analyzed for its effective results and then adjusted accordingly in any school. In that way, when the applied system creates problems in a majority of cases, it means that the strategy still needs to be refined further to achieve the desired objectives.

\section{Using Advanced Technologies}

The latest technologies such as social media and the web can be employed to assign colors to the students' actions. The student who got a particular card will have his data uploaded onto the school pages and accessed by parents, so we can collect feedback from parents to enhance class management. Using the latest technology helps the parents to know about their children and to give feedback easily.

\section{Methodology}

To keep the students in a routine and disciplined student life, there are rules and regulations made for them. In the K-12 system, students can be easier to manage with the help of the systematic approaches used in most schools. When these students go to universities or colleges, however, they are more mature and can be more resistant to the authority of the teacher. To achieve better school management at this stage of the educational process, the color coded cards system has been proposed, and was used in the classes studied in this research project. In this system, cards were given to the students according to their behavior in the class. The following behaviors were considered as misconduct behaviors in the class:

- Talking to other students

- Talking on the cellular phone

- Using the laptop or any electronic devices

- Using the chat on the smart-phone 
- Not switching the cellular phone to silent mode, etc.

The study was conducted in Saudi Arabia starting in spring 2013 and continuing until fall 2015. The institutions that were studied are King Abdul Aziz University (KAU) with 100 students (70\% girls and 30\% boys, of which $50 \%$ are graduates and 50\% are undergraduates), Effat University with 100 students (all undergraduate girls), UMM Alqura University (UQU) with 80 students (girls to boys ratio of 4:1, all at undergraduate level) and College of Technology, Makkah, (70 undergraduate boys).

While a teacher presents a lecture in the class, each of the above behaviors is considered a misconduct. Each time a student commits one of these offences a color coded card is given to him or her; the color of the card represents the student's behavior and attentiveness. Better colors indicate good behavior, while worse colors show less attentiveness or bad behavior. There are four colors in the system. Yellow is given to the student when he or she misconducts only one time during the class time. If the student misconducts again (the same action) during the same class time, then he or she gets a red card which means a penalty. The other two colors are white and green. These are rewarding colors. If a student behaves, then he or she could be rewarded with a green card. On the other hand, white cards are given to the students with outstanding attention or performance in the class.

For this research, the students' opinions were considered after a successful session in which the color coded card system was used. Students' opinions were collected using a questionnaire that was carefully designed to allow respondents to express precise opinions about all the main points of the research topic. The questionnaires were delivered to the students at the institutions participating in the research and the response rate was almost 100\% (Savenye, W. C., \& Robinson, R. S, 2004). The entire color coded cards system was observed properly, then the questionnaire was designed. It was designed in such a way that the students could answer all the questions properly, and not miss any of the questions. The questions were printed on a single page because in many cases it was observed that a person fails to answer the questions on pages other than the first. The questions were Multiple Choices Questions (MCQ); the students had to put a tick mark on their answer corresponding to their opinion. Different questions had different scales, such as "yes or no," "bad, good, or very good," etc.

Before the questionnaire was distributed to the students a pilot survey was conducted to show whether any point was missing. Expert advice was taken when designing the questionnaire to ensure that all the needed information was included and filled in. To collect the answered questionnaires there were several boxes in each academic building, so the students could easily submit them.

\section{Results}

The questionnaire was as follows: 
Table 1

\section{Questionnaire}

1. What is your perception of the color coded cards system?
I. Excellent
Good
Makes no difference

2. Which color do you think more effective among your classmates?
II. Yellow
Red
Green
White

3. Do you think some of your classmates have had a behavior change based on this system?

III. Yes No Maybe

4. Devices and behavior affected by this system?

IV. Mobile Laptop or iPad

Other electronic devices

Talking Others

5. Did you discuss this system with friends, family members or anyone other than your classmates?

V. Yes No

6. Do you think this system is effective in class management?
VI. Yes
No
Maybe

The questionnaire was delivered to 350 students, as described above. Also as noted above, almost all of the students completed the questionnaires and submitted them. However, some of the questionnaires were not taken into account because they did not have precise answers. 
Table 2

\section{Results of the Questionnaire}

1. What is your perception of the color coded cards system?
VII. Excellent $66.48 \%$;
Good 22.04\%;
Makes no difference $11.48 \%$

2. Which color do you think more effective among your classmates?
VIII. Yellow 42\%;
Red 33\%;
Green $8 \%$;
White $17 \%$

3. Do you think some of your classmates have had a behavior change based on this system?
IX. Yes $74.85 \%$;
No $10 \%$;
Maybe $15.15 \%$

4. Devices and behavior affected by this system?

X. Mobile 32.13\%; Laptop or iPad 9.45\%; Other electronic devices 29\%; Talking 24\%; Others $5.42 \%$

5. Did you discuss this system with friends, family members, or anyone other than your classmates?
XI. Yes $76.82 \%$;
No $23.18 \%$

6. Do you think this system is effective in class management?
XII. Yes $76.52 \%$;
No $19.66 \%$;
Maybe $3.82 \%$

When the students were asked about their perception of the color coded cards system, only $11.48 \%$ of the students replied that they did not see any difference after the system was applied in the class, while $22.03 \%$ felt the system was a good tool of class management, and $66.48 \%$ felt the system was excellent. Figure 1 shows the result.

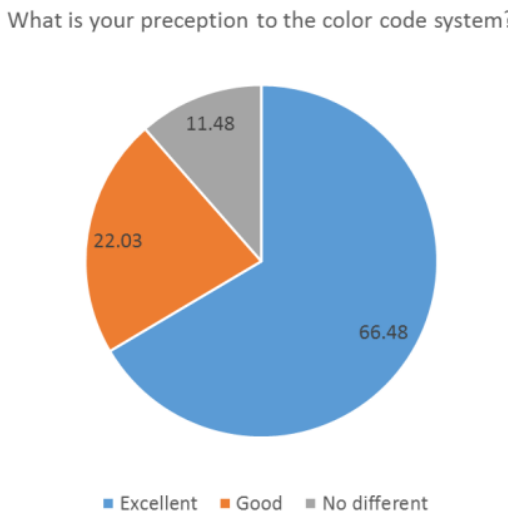

Figure 1. Perception of the system.

When the students were asked about which color they think is most effective among their classmates, $42 \%$ of them selected the yellow color. This indicates that it is quite difficult to pass the entire class-time by maintaining all the rules and regulations. Some of the problems occur accidentally or due to an absent mind or the student's deciding that a few rules can be avoided or violated. On the other hand, $33 \%$ of the students 
thought the red card was more effective. This means that a significant portion of the students violate or avoid more than one rule set by the authority. On the positive side, $17 \%$ of the students wanted to see their classmates with a white color, and only $8 \%$ wanted to see their classmates with a green color. Figure 2 shows the results.

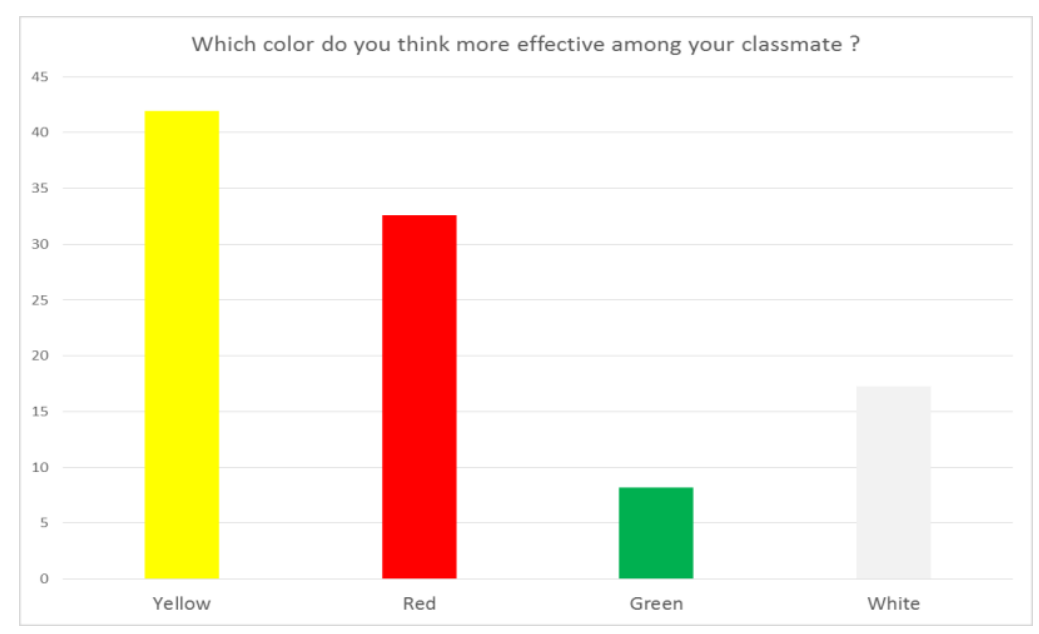

Figure 2. The effectiveness of each color.

In the third question, the students were asked to indicate if they observed a change in the behavior of their classmates. Almost three quarters of students replied yes, the system had changed the behavior of their classmates. Only $10 \%$ students said no, while $15.15 \%$ were not sure. This indicates that the class management system had a visible effect. The result is shown in Figure 3.

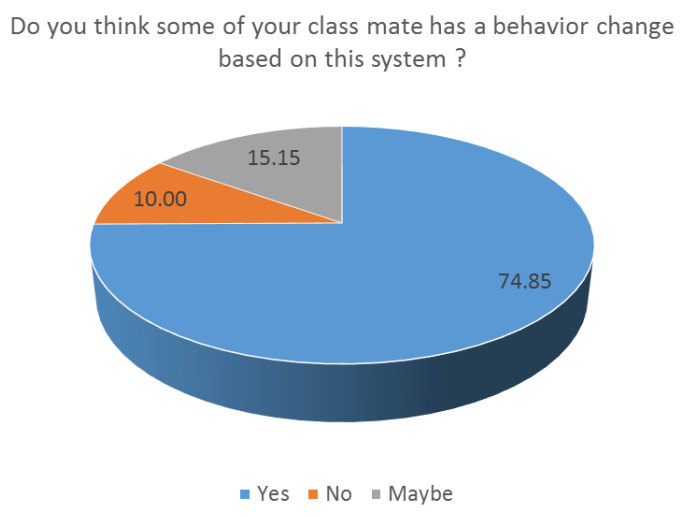

Figure 3. Behavior changes.

The fourth question was about the devices that students used for various purposes. There were five options in the answer: mobile, laptop or iPad, other electronic devices, talking, and others. Some of the students have a mobile, laptop, and iPad; some of them have only a mobile and a laptop or iPad; and some of the students have only one of the devices. The results show that the use of mobiles was affected significantly (32.13\%), a reduction of the time spent on mobile phones being observed. A reduction of time of use for other electronic devices was also observed. Refer to Figure 4. 


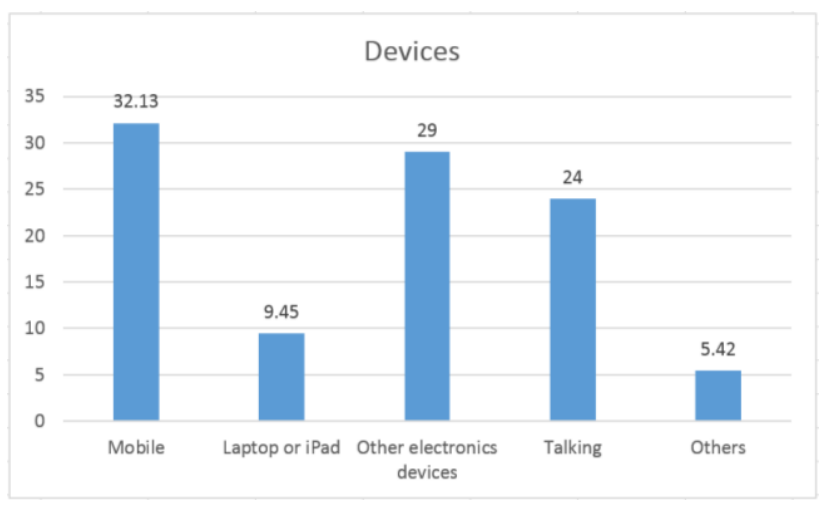

Figure 4. Devices.

Did you discuss about this system with friends, family mameber or anyone other than your classmates?

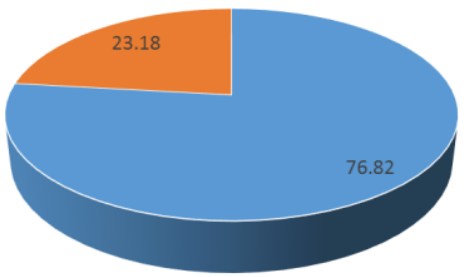

- Yes = No

Figure 5. Results of question 5.

The students were asked to state whether they had discussed the color coded cards system with their family members, or friends, or anyone other than their classmates. The responses showed that $76.82 \%$ of students had discussed the color coded cards system with their family members or friends other than classmates. Only $23.18 \%$ of the students did not discuss the system with anyone except classmates. That the system had been discussed by the students outside the classroom indicates how much the students were interested in the color system. The result of this question is presented in Figure 5 .

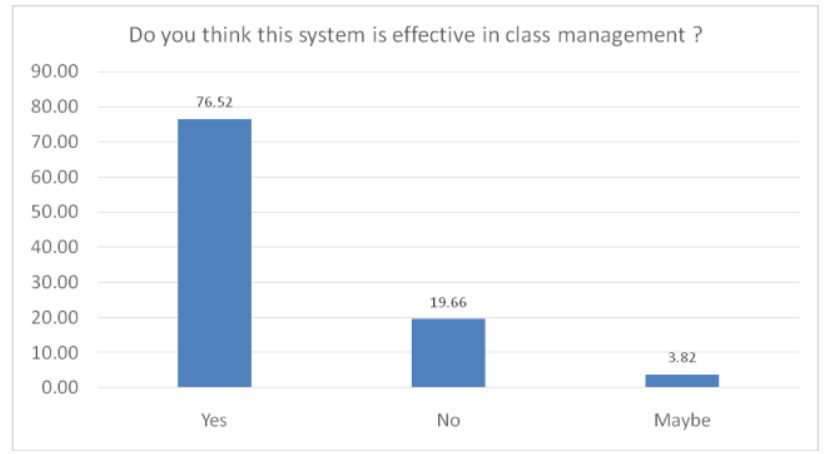

Figure 6. The effectiveness of the system in class management. 
When the students were asked about the color coded cards system, whether the system is effective in class management or not, $76.52 \%$ of the students answered that the system is effective. Only $19.56 \%$ indicated that they did not feel any productive result, while $3.82 \%$ were not sure. Figure 6 shows the results.

This research was conducted to identify whether the color coded cards system is an effective class management tool for the students, teachers, and the school; a survey was conducted with a questionnaire consisting of six questions. Achieved results are presented in the result section in this report, based on the responses submitted by the 350 students who took part in the survey. The questionnaire was designed in such a way that the students could answer about the color coded cards system very precisely and clearly just by ticking the appropriate option according to their opinions. The color coded cards system was thought to be an excellent tool for class management by $66.48 \%$ of the students, while $74.85 \%$ thought that the system had changed the behaviors of at least some students. And $76.52 \%$ students thought that the color coded cards system is an effective system for class management.

The results clearly showed that the students have changed their behavior and have become more attentive to the class. More attention means more study and better results. Regarding question 4, "Devices and behavior effected by this system?" many of these devices could be used by the students to get the latest knowledge related to their studies; however, these devices can be harmful if they are being used for entertainment purposes during class time. The students' use of mobile phones and talking during class time was reduced significantly when the color coded cards system was used.

The results also show that the students are more aware of using their electronic gadgets like mobile phones, laptops, or iPads. They learned to use these devices more effectively and get more benefits from those devices in their practical lives. The students understood that switching their phones to a silent mode and replying to calls or messages during the breaks is an action that ensures more attention to the class and thus leads to a better understanding of the subject matter of the courses, leading to better grades.

To this point, all the positive aspects of the application of the color coded cards system have been discussed. There could be some negative aspects; they are negligible when compared to the total number of students in the school. That there could be a series of specific actions that were common to systems that are shame-based had been taken into consideration (Winch, Todd, Baker, Blain, \& Smith, 2014). In some cases, the application of this class management system may not produce the desired effects and may not be productive. Such an outcome can have a negative impact on the student; however, only a small percentage of students may suffer from such problems (Lynch, 2013).

\section{Conclusions}

The color coded cards system is a tool that can be applied to achieve better class management in schools and universities. When the teachers, educators, and other administrators want to manage their institutions more effectively, the color coded cards system can be an excellent solution for them. In this research, two different systems were analyzed, based on the academic literature. In both systems, certain colors are being used to show the behavioral activities of the students in the class. In the pocket chart system, the color coded cards were kept in one place and the cards were changed if there was any improvement in the behavior of the student. This system will help institutions to communicate efficiently with the students' guardians, using the color coded 
cards system as a tool for feedback. Such communication can be done using social media, mobile app, the institution's website as well as some other means.

The second part of the study is related to the application of the color coded cards system with groups of students, using a questionnaire to indicate their perceptions of the results.

When students are marked for their misconducts (by being listed on the chart or marked with a yellow or red card) then they try to remove themselves from that list/chart by improving their behavior. This happens in almost three cases out of four, and is a good motivator for positively reinforcing behavior and good actions in every social environment. The negative impact of this system is significant and can be eliminated by taking special care of the predisposed students (according to their psychological makeup).

The research was conducted successfully and an excellent result was achieved. The system can be implemented with relative ease in schools and universities in order to obtain better class management. It can be improved by using digital technologies such as a digital board on the front wall of the classroom or by using digital color tags with the help of the digital gadgets and wireless systems on the campuses.

\section{References}

Boe, T., Gulbrandsen, B., \& Sorebo, O. (2015). How to stimulate the continued use of ICT in higher education: Integrating information systems continuance theory and agency theory. Computers in Human Behavior, 5o, 375-384.

Buckley, S. (2012). Higher education and knowledge sharing: From ivory tower to twenty-first century. Innovations in Education and Teaching International, 49(3), 333-344.

Crawford, G. B. (2004). Managing the adolescent classroom: Lessons from outstanding teachers. Thousand Oaks, CA: Corwin Press.

Emerson, E. (1995) Challenging behavior: Analysis and intervention in people with learning disabilities. New York: Cambridge University Press.

Emmer, E. T., \& Sabornie, E. J. (Eds.) (2015). Handbook of classroom management (2nd ed.). New York: Routledge.

Lynch, M. (2013). Future trends in K-12 classroom management and discipline [Web log post]. Retrieved from http://blogs.edweek.org/edweek/education futures/2013/11/future trends in k12 classroom management and discipline.html

Rios, J. (2016). Behavior strategies that promote academic achievement for students with emotional and behavioral disorders within the inclusive classrooms: A thesis in education with a major in special education (Master's thesis). Indiana University-Purdue University Fort Wayne.

Savenye, W. C., \& Robinson, R. S. (2004). Qualitative research issues and methods: An introduction for educational technologies. In D. H. Jonassen, \& P. Harris (Eds.), Handbook of research for educational communications and technology (pp. 1045-1071). Mahwah, NJ: Lawrence Erlbaum Associates. 
Shindler, J. (2009). Transformative classroom management: Positive strategies to engage all students and promote a psychology of success. Jossey-Bass, San Francisco, CA

Starr, L. (2010). Creating a climate for learning [Web log post]. Education World. Retrieved from http://www.educationworld.com/a curr/curr155.shtml

Sugai, G., Horner, R. H., Dunlap, G., Hieneman, M., Lewis, T. J., Nelson, C. M. ... \& Turnbull, H. R. (2000). Applying positive behavior support and functional behavioral assessment in schools. Journal of Positive Behavior Interventions, 2(3), 131-143.

Winch, C., Todd, M., Baker, I., Blain, J., \& Smith, K. (2014). Guide to undergraduate dissertations in the social sciences: Methodologies. Retrieved from http://www.socscidiss.bham.ac.uk/methodologies.html

Zhang, X., Gao, Y., Yan, X., Ordóñez de Pablos, P., Sun, Y., \& Cao, X. (2015) From e-learning to sociallearning: Mapping development of studies on social media-supported knowledge management. Computers in Human Behavior, (51)B, 803-811.

\section{Athabasca \\ University}

(9) (1) 